\title{
Flaxseed gum-biopolymers interactions driving rheological behaviour of oropharyngeal dysphagia-oriented products
}

\author{
J.M. Vieira ${ }^{\mathrm{a}, \mathrm{b}}$, C.C.P. Andrade ${ }^{\mathrm{a}, \mathrm{b}}$, T.P. Santos ${ }^{\mathrm{a}}$, P.K. Okuro ${ }^{\mathrm{a}}$, S.T. Garcia ${ }^{\mathrm{a}}$, M.I. Rodrigues ${ }^{\mathrm{a}}$, A. \\ A. Vicente ${ }^{\text {b }}$, R.L. Cunha ${ }^{a, *}$ \\ ${ }^{a}$ Department of Food Engineering, Faculty of Food Engineering, University of Campinas (UNICAMP), 13083-862, Campinas, SP, Brazil \\ ${ }^{\mathrm{b}}$ Centre of Biological Engineering (CEB), University of Minho, Campus de Gualtar, 4710-057 Braga, Portugal
}

\section{A R T I C L E I N F O}

\section{Keywords:}

Dysphagia

Thickeners

Flaxseed gum

Rheology

Glucose load

\begin{abstract}
A B S T R A T
Viscosity-modified diet through thickeners is used as a strategy to circumvent swallowing problems by oropharyngeal dysphagia patients. Most commercial products present xanthan and starch in their formulations, but flaxseed gum (FG) is a potential thickener for liquid food that provides additional health benefits. FG was mixed either with modified starch (MS) and/or xanthan gum (XG), varying biopolymers' concentration according to a central composite rotational design in which rheological and colour properties in water were the evaluated responses. All formulations showed a shear time-independent and shear-thinning behaviour, mainly influenced by XG and MS concentrations. In oscillatory measurements, the formulations presented a prevailing elastic character attributed to MS and mainly to XG, which despite the lower concentration in which it was incorporated, exerted a similar influence on this rheological property. However, the increase of FG concentration was the most significant factor influencing viscosity, but also favoured an increase of both viscoelastic moduli mainly $G^{\prime}$. Analysis of the microstructure disclosed different network structures as a result of biopolymers interactions, which was related to rheological behaviour giving insights to design new thickeners for dysphagia management. In addition, the amount of glucose released after in vitro digestion was evaluated and compared to a commercial MS-based thickener. Interestingly, the commercial formulation showed a glucose release significantly higher than the proposed FG/MS/XG-based formulations. These results open the opportunity to tailor the rheological characteristics of food systems by adding and combining natural ingredients, improving technological and nutritional properties.
\end{abstract}

\section{Introduction}

Oropharyngeal dysphagia is the most prevalent and severe stage of dysphagia, since this pharyngolaryngeal sensitivity is a swallowing dysfunction, occurring during food transition from the mouth to the esophagus. This mechanical disorder may be associated with aging, neurological complications, brain and neck cancer, cerebral palsy, Huntington's, Parkinson's or Alzheimer's diseases, benign esophageal stricture, cerebrovascular accident among others (Leonard, White, McKenzie, \& Belafsky, 2013; Mackley et al., 2013). Consequently, dysphagia can cause undernutrition, dehydration, aspiration pneumonia and even, in extreme cases, death (Garin et al., 2014; Leonard et al., 2013; O'Leary, Hanson, \& Smith, 2010). As a strategy to overcome the difficulty to swallow by the dysphagia patients, texture modification of liquid food using natural thickeners (biopolymers) has been investigated
(Clavé \& Shaker, 2015; September, Nicholson, \& Cichero, 2014). In this approach, viscosity is increased in order to increase bolus passage time from the mouth to the throat and allowing thereby a longer reflective response by the muscles that are responsible for swallowing when it enters in the pharynx and, posteriorly, reaches the larynx. However, an excessive thickening may origin negative effects, such as reducing the palatability, as in addition to increasing viscosity, there can also be changes in consistency and cohesiveness. For these reasons, different rheological parameters (e.g. flow properties, oscillation measurements and extensional viscosity) of the thickened liquid food, as well as the visual appearance (e.g. aspect and colour) should be taken into account since both are critical factors when considering dysphagia patients' acceptance of a liquid food (Dewar \& Joyce, 2006a,b; Hori et al., 2015; Nishinari, Turcanu, Nakauma, \& Fang, 2019).

Generally, beverage thickeners available on the market are

\footnotetext{
* Corresponding author.

E-mail address: rosiane@unicamp.br (R.L. Cunha).
} 
comprised of pre-gelatinized modified starch and/or xanthan gum. In some cases, other polysaccharides, such as guar gum or maltodextrin, can be added as gelling agents (Moret-Tatay, Rodríguez-García, Martí-Bonmatí, Hernando \& Hernandez, 2015). Starch is a low-cost ingredient that consists mainly of two $\alpha-1,4-\mathrm{D}-$ glucose polymers: the almost linear amylose and the highly branched [5-6\% $\alpha-1,6$-linkages] amylopectin. Pre-gelatinization of the starch is necessary to convert starch into a soluble form in order to be completely dispersed and show fast viscosity development as necessary for an ingredient in dysphagia diet (Kanmani et al., 2018; Tako, Tamaki, Teruya, \& Takeda, 2014; Tester, Karkalas, \& Qi, 2004). However, the high glucose load is a critical point of this polysaccharide, since its ingestion can result in either aggravation or development of chronic metabolic diseases; this means that more studies are needed in order to find alternatives. Moreover, starch is partly hydrolysed in the mouth by the amylase from saliva, decreasing the viscosity of the thickened foods. Unlike starch, gums do not need additional treatment and are not degraded by saliva amylase, keeping the viscosity more stable during the swallowing process (Leonard et al., 2013; Torres et al., 2019; Vallons, Helmens, \& Oudhuis, 2015). Xanthan gum (XG) is a high molecular weight heteropolysaccharide that presents 1,4 -linked $\beta$-D-glucose residues as the primary structure and trisaccharide side chains with two molecules of mannose and one glucuronic acid linked to D-glucose at the backbone (Jo, Bak, \& Yoo, 2018). This hydrophilic colloid is an anionic polymer stable in a wide range of temperature and $\mathrm{pH}$ values. As thickener, XG presents the advantage of being well accepted in terms of viscosity/texture by dysphagia patients when incorporated into beverages, due to its particular flow properties showing pronounced shear-thinning behaviour, owing to a rigid and rod-like conformation (Achayuthakan \& Suphantharika, 2008; Jo et al., 2018).

Flaxseed gum is a by-product of oil industry that is found in the flaxseed hulls. The soluble part of the flaxseed gum (FG) is a promising biopolymer to be incorporated into a thickening product, capable of responding to the difficulties presented by dysphagia patients, since it exhibits thickening capacity coupled to nutritional properties (Vieira et al., 2019). FG is mainly composed of neutral and acidic polysaccharides with a small fraction of proteins (5-10\% depending on extraction temperature) (Cui, Mazza, \& Biliaderis, 1994; Elboutachfaiti et al., 2017; Qian, Cui, Nikiforuc \& Goff, 2012). The main sugar of the neutral fraction of the polysaccharides is xylose, followed by arabinose, galactose and glucose, whereas the acidic fraction is mainly composed of uronic acids, and also rhamnose and galactose (Cui, Kenaschuk \& Mazza, 1996; Vieira et al., 2019). FG also presents phenolic compounds that could exhibit pharmacological properties including antidiabetic, antihypertensive, immunomodulatory, anti-inflammatory and neuroprotective properties (Vieira et al., 2019). Moreover, FG fibres intake can improve intestinal tract transit, promoting an improvement in postprandial glycemia and weight control, reducing risk of diabetes and coronary heart diseases and decreasing cholesterol, besides preventing colorectal cancer and other health benefits (Ding et al., 2014; Foster-Powell, Holt, \& Brand-Miller, 2002; Liu, Shim, Poth, \& Reaney, 2016; Morris \& Vaisey-Genser, 2003, pp. 2525-2531).

Usually, modified liquid foods targeted for dysphagia patients are described according to recommendations from the guidelines of the National Dysphagia Diet (NDD), elaborated in 2002 by the American Dietetic Association. In the attempt to standardize the viscosity of liquid foods for dysphagia diets, four levels of consistency have been suggested: (i) Thin (1-50 cP (or mPa.s)), (ii) Nectar-like (51-350 cP (or mPa.s)), (iii) Honey-like (351-1750 cP (or mPa.s)) and (iv) Spoon or Pudding thick ( $>1750 \mathrm{cP}$ (or $\mathrm{mPa} . \mathrm{s}$ )). However, only the last three are recommended in the palliative care of dysphagia patients (Zargaraan, Rastmanesh, Fadavi, Zayeri, \& Mohammadifar, 2013). In general, the addition of thickeners to food formulations modifies their rheological properties, which become shear-thinning fluids, and, in some cases, with yield stress, which is associated with the cohesiveness. Cohesiveness is related to the ability to maintain the internal structure against the application of deformation and this property can be evaluated from rheological properties obtained under extensional flow as the force at break (Nishinari et al., 2019). A shear-thinning behaviour means that viscosity decreases with an increase of shear rate. The shear rate exerted on the food varies according to the physiological capacity of the oral cavity, the level of dysphagia of each patient and also the physicochemical properties of the ingested food. Thus, although Wood (1968) has stated that the shear rate during swallowing is around $50 \mathrm{~s}^{-1}$ (used as a reference by the National Dysphagia Diet - NDD and by many scientific researches), there is limited scientific evidence for this standard, and oral process shear rates may range from 10 to $1000 \mathrm{~s}^{-1}$ (Shama \& Sherman, 1973). A shear rate of $10 \mathrm{~s}^{-1}$ for liquids could be more reasonable according to Cutler, Morris, and Taylor (1983), but Meng, Rao, and Datta (2005) proposed $400 \mathrm{~s}^{-1}$ as an indicator of oral shear rates. Therefore, several authors have reported that the shear rate definition given by NDD is inconclusive and subjective. The International Dysphagia Diet Standardization Initiative (IDDSI) built and made available in 2015 a framework based on global standards and guidelines to obtain a worldwide terminology for different consistencies, covering all cultures and ages. This categorization results from the analysis of the consistency of thickened foods using simple and easy methods to quantify the movement of these foods based on their flow rate as thin (level 0, flows like water), slightly thick (level 1, slightly thicker than water), mildly thick (level 2, flows off a spoon), moderately thick (level 3, will not hold its shape on a spoon), and extremely thick (level 4, holds shape on spoon) to represent the thickening of the drinks (Nishinari et al., 2019; Ong, Steele, \& Duizer, 2018). However, for the development of a new thickener formulation that ensures a suitable and quantifiable product, a complete rheological analysis under shear and extensional forces, applying different magnitudes of forces (as for example flow curves and oscillatory rheology) or shear rates/frequencies is essential to guarantee the safety of the new product for dysphagia patients (Hadde \& Chen, 2019). This is because oral and pharyngeal flow is complex and thus, the in vivo behaviour of a material cannot be fully characterised by any metric. Therefore, other rheological parameters, such as the flow index (n), complex viscosity at $50 \mathrm{rad} \mathrm{s}^{-1}$ and the relation between $G^{\prime}$ (storage modulus, representing elastic behaviour) and $G$ " (loss modulus, associated to viscous behaviour), may give extra information about the sensory consistency of foods, allowing to draw some conclusions about the possibility to returning the pleasure of swallowing to these patients with restricted diet (Richardson, Morris, Ross-Murphy, Taylor, \& Dea, 1989).

Due to the significant increase in the number of dysphagia patients, the need to intensify the development of new scientific research in the area is a reality, which would help in the recovery and well-being of patients due to better and pleasurable nutrition. For this, a detailed evaluation of the thickened fluid food (colorimetric analyses, microscopy and rheological behaviour) was performed, as well as a study of the glucose supply of these potential thickeners after their intake. These thickeners were composed by FG, MS and XG in different concentration following a central composite rotational design allowing to understand the effect of each polysaccharide on rheological properties. Therefore, the aim of this work was to design new alternative thickeners, which should be safe and capable of responding to the needs of different groups of dysphagia patients.

\section{Material and methods}

\subsection{Material}

Golden flaxseeds were kindly provided by CISBRA Ltda (Panambi, RS, Brazil). Xanthan gum (XG) and modified (pregelatinized) starch (MS) were donated by Danisco (Brazil) and Cargill (Brazil), respectively. The starch-based commercial thickener (CT) was purchased from a local pharmacy (São Paulo, Brazil). The following salts were used to prepare simulated digestion fluids: $\mathrm{KCl}, \mathrm{NaHCO}_{3}, \mathrm{NaCl}, \mathrm{MgCl}_{2}\left(\mathrm{H}_{2} \mathrm{O}\right)_{6}$, 
Table 1

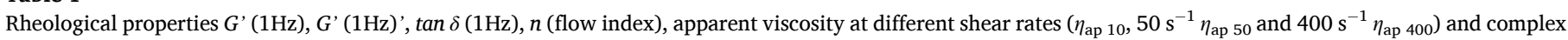

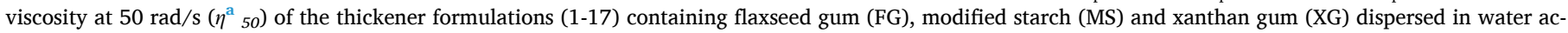
cording to CCRD matrix.

\begin{tabular}{|c|c|c|c|c|c|c|c|c|c|c|c|}
\hline \multirow[t]{2}{*}{$\mathrm{TF}$} & \multirow{2}{*}{$\frac{\mathrm{FG}\left(x_{1}\right)}{(\%)}$} & \multirow{2}{*}{$\frac{\operatorname{MS}\left(x_{2}\right)}{(\%)}$} & \multirow{2}{*}{$\begin{array}{l}\mathrm{XG}\left(x_{3}\right) \\
(\%)\end{array}$} & \multirow{2}{*}{$\frac{\eta_{a p 10}}{(\mathrm{mPa} . \mathrm{s})}$} & \multirow{2}{*}{ 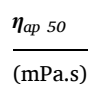 } & \multirow{2}{*}{$\frac{\boldsymbol{\eta}_{a p} 400}{(\mathrm{mPa} . \mathrm{s})}$} & \multirow{2}{*}{$\frac{\eta^{\mathrm{a}} 50}{(\mathrm{mPa} . \mathrm{s})}$} & \multirow[t]{2}{*}{$n$} & \multirow{2}{*}{$\frac{G^{\prime}(1 \mathrm{~Hz})}{(\mathrm{Pa})}$} & \multirow{2}{*}{$\frac{G^{\prime \prime}(1 \mathrm{~Hz})}{(\mathrm{Pa})}$} & \multirow{2}{*}{$\frac{\operatorname{Tan} \delta}{(1 \mathrm{~Hz})}$} \\
\hline & & & & & & & & & & & \\
\hline 1 & $-1(0.6)^{a}$ & $-1(0.6)$ & $-1(0.1)$ & 105 & 57 & 26 & 150 & 0.62 & 0.66 & 0.83 & 1.26 \\
\hline 2 & $1(2.4)$ & $-1(0.6)$ & $-1(0.1)$ & 1265 & 529 & 172 & 1150 & 0.46 & 11.25 & 7.54 & 0.67 \\
\hline 3 & $-1(0.6)$ & $1(2.4)$ & $-1(0.1)$ & 568 & 206 & 56 & 1800 & 0.37 & 6.05 & 5.64 & 0.93 \\
\hline 4 & $1(2.4)$ & $1(2.4)$ & $-1(0.1)$ & 2652 & 1064 & 327 & 3100 & 0.43 & 16.76 & 14.83 & 0.89 \\
\hline 5 & $-1(0.6)$ & $-1(0.6)$ & $1(0.4)$ & 705 & 274 & 81 & 1300 & 0.41 & 8.62 & 4.37 & 0.51 \\
\hline 6 & $1(2.4)$ & $-1(0.6)$ & $1(0.4)$ & 908 & 477 & 287 & 550 & 0.52 & 4.17 & 6.17 & 1.48 \\
\hline 7 & $-1(0.6)$ & $1(2.4)$ & $1(0.4)$ & 1275 & 440 & 112 & 4500 & 0.34 & 21.79 & 10.54 & 0.48 \\
\hline 8 & $1(2.4)$ & $1(2.4)$ & $1(0.4)$ & 4199 & 1528 & 414 & 8700 & 0.37 & 57.98 & 25.00 & 0.43 \\
\hline 9 & $-1.68(0)$ & $0(1.5)$ & $0(0.25)$ & 229 & 80 & 21 & 700 & 0.35 & 4.31 & 2.70 & 0.63 \\
\hline 10 & $1.68(3)$ & $0(1.5)$ & $0(0.25)$ & 3356 & 1299 & 381 & 3760 & 0.41 & 21.90 & 16.70 & 0.60 \\
\hline 11 & $0(1.5)$ & $-1.68(0)$ & $0(0.25)$ & 387 & 190 & 76 & 670 & 0.56 & 3.71 & 2.99 & 0.81 \\
\hline 12 & $0(1.5)$ & $1.68(3)$ & $0(0.25)$ & 2553 & 931 & 253 & 5800 & 0.37 & 37.69 & 19.69 & 0.52 \\
\hline 13 & $0(1.5)$ & $0(1.5)$ & $-1.68(0)$ & 458 & 241 & 105 & 280 & 0.60 & 0.67 & 1.73 & 2.58 \\
\hline 14 & $0(1.5)$ & $0(1.5)$ & $1.68(0.5)$ & 2303 & 776 & 190 & 4610 & 0.32 & 32.17 & 13.30 & 0.41 \\
\hline 15 & 0 (1.5) & $0(1.5)$ & $0(0.25)$ & 983 & 442 & 127 & 1930 & 0.49 & 8.90 & 5.37 & 0.60 \\
\hline 16 & $0(1.5)$ & $0(1.5)$ & $0(0.25)$ & 1023 & 451 & 142 & 1910 & 0.50 & 9.50 & 6.19 & 0.65 \\
\hline 17 & $0(1.5)$ & $0(1.5)$ & $0(0.25)$ & 996 & 422 & 139 & 1940 & 0.47 & 8.27 & 5.99 & 0.72 \\
\hline
\end{tabular}

a Coded and uncoded values (in parenthesis) representing biopolymers concentration.

$\left(\mathrm{NH}_{4}\right)_{2} \mathrm{CO}_{3}, \mathrm{HCl}, \mathrm{CaCl}_{2}\left(\mathrm{H}_{2} \mathrm{O}\right)_{2}, \mathrm{NaOH}$ (Merck, Germany) and $\mathrm{KH}_{2} \mathrm{PO}_{4}(\mathrm{~J}$. T. Baker, USA). The digestive enzymes porcine $\alpha$-amylase (A3176, 9.65 $\mathrm{U} \mathrm{mg}{ }^{-1}$ solid), porcine pepsin (P6887, 2512.16 $\mathrm{U} \mathrm{mg}^{-1}$ solid), and pancreatin (P7545, trypsin activity at $\mathrm{pH} 8.1$ and $25{ }^{\circ} \mathrm{C}: 6.07 \mathrm{U} \mathrm{mg}^{-1}$ pancreatin) were purchased from Merck (Germany), and porcine bile extract (sc-214,601) was supplied by Santa Cruz Biotechnology (USA). Glucose Activity Assay Kit was bought from LaborLab (Brazil).

\subsection{Extraction of FG and preparation of thickeners}

FG was obtained at $25{ }^{\circ} \mathrm{C}$ according to Vieira et al. (2019). The extracted FG, used in the present work, contained approximately $67 \%$ of carbohydrates, $5 \%$ of protein and $13 \%$ of phenolic compounds. Thickener formulations were prepared by dissolving FG, MS and XG in distilled water under mechanical stirring during $30 \mathrm{~min}$ at $800 \mathrm{rpm}$ and room temperature $\left(25^{\circ} \mathrm{C}\right)$ to obtain a homogeneous solution. Then, samples were rested for an hour before being subjected to further analyses. Formulations were prepared following an experimental design described in section 2.3.

\subsection{Experimental design}

A Central Composite Rotational Design (CCRD) $2^{3}$, added of three replicates at the central point and six axial point essays, was performed for the three thickeners (FG, MS and XG) chosen based on a preliminary experimental design (Plackett-Burman Design, data not showed) using five polysaccharides (FG, MS, XG, guar gum and pectin). Solutions of each single biopolymer (FG, MS or XG) were prepared at intermediate and maximum studied concentrations and considered as control systems. Independent variables, $x_{1}=\mathrm{FG}\left(0-3 \%\right.$, w/v), $x_{2}=\mathrm{MS}(0-3 \%$, w/ v) and $x_{3}=\mathrm{XG}(0-0.5 \%, \mathrm{w} / \mathrm{v})$, were studied (for details on formulations, please see Table 1 in section 3.2 below) based on the importance of each compound for the following responses (dependent variables): viscosity $(\eta)$ at different shear rates $\left(10,50\right.$ and $\left.400 \mathrm{~s}^{-1}\right)$, complex viscosity at 50 $\mathrm{rad} / \mathrm{s}\left(\eta^{*}\right)$, flow index $(n)$, storage $\left(G^{\prime}\right)$ and loss $\left(G^{\prime \prime}\right)$ moduli. Analysis of variance (ANOVA) of statistically significant regression coefficients $(p<$ 0.1 ) was used to evaluate predictive models. Then, the response surfaces and contour curves were plotted in order to estimate the concentration range of each formulation's component according to the targeted rheological properties. One formulation representing each categorization of the NDD guidelines (using $\eta$ at $50 \mathrm{~s}^{-1}$ ) was predicted and experimentally validated aiming at verifying the efficiency of the models. All experimental design analyses were performed by Protimiza software (http://experimental-design.protimiza.com.br).

\subsection{Rheological measurements}

Rheological properties of thickeners' solutions were obtained using an AR1500ex rheometer (TA Instruments, USA) with a stainless-steel cone-plate geometry $\left(6.0 \mathrm{~cm}, 2^{\circ}\right.$ angle, truncation $\left.67 \mu \mathrm{m}\right)$. All the measurements were performed at $25{ }^{\circ} \mathrm{C}$. Flow curves were obtained by an up-down-up step program using different shear stresses range to provide shear rate ranging from 0 to $400 \mathrm{~s}^{-1}$. Newtonian (Eq. (1)) and power-law models (Eq. (2)) were fitted to the data to obtain rheological properties.

$\sigma=\eta \cdot \dot{\gamma}$

$\sigma=k \cdot \dot{\gamma}^{n}$

where $\sigma$ is the shear stress (Pa), $\eta$ is the viscosity (Pa.s), $k$ is the consistency index $\left(\mathrm{Pa} . \mathrm{s}^{\mathrm{n}}\right), \dot{\gamma}$ is the shear rate $\left(\mathrm{s}^{-1}\right)$ and $n$ is the flow index.

The viscoelastic properties were evaluated using a frequency sweep between 0.1 and $10 \mathrm{~Hz}$ within the linear viscoelasticity domain. The contributions of the elastic and viscous characteristics were analysed from storage $\left(G^{\prime}\right)$ and loss $\left(G^{\prime \prime}\right)$ moduli, respectively. The loss tangent $(\tan \delta)$ was evaluated to define the prevailing behaviour elastic or viscous. Tan $\delta<1$ indicates a predominantly elastic behaviour, whereas $\tan \delta>1$ denotes a predominantly viscous behaviour, that is directly related to the energy lost per cycle divided by the energy stored per cycle (Eq. (3)). The complex viscosity ( $\left.\eta^{*}\right)$ (Eq. (4)) was calculated since this property can be also correlated to the perception of thickness (He, Hort, \& Wolf, 2016), especially of viscoelastic materials.

$\tan \delta=\frac{G^{\prime}}{G}$

$\eta^{*}=\frac{G^{*}}{\omega}$

where $\delta$ is the phase angle between the applied strain and the stress response, $G^{*}$ is the complex modulus and $\omega$ is the angular frequency.

The level of difficulty to chew and/or swallow food by dysphagia patients can vary considerably, which causes a clinical practice problem, and this may complicate medical follow-up and increase the medical errors (Germain, Dufresne, \& Ramaswamy, 2006). Thus, the effects of 

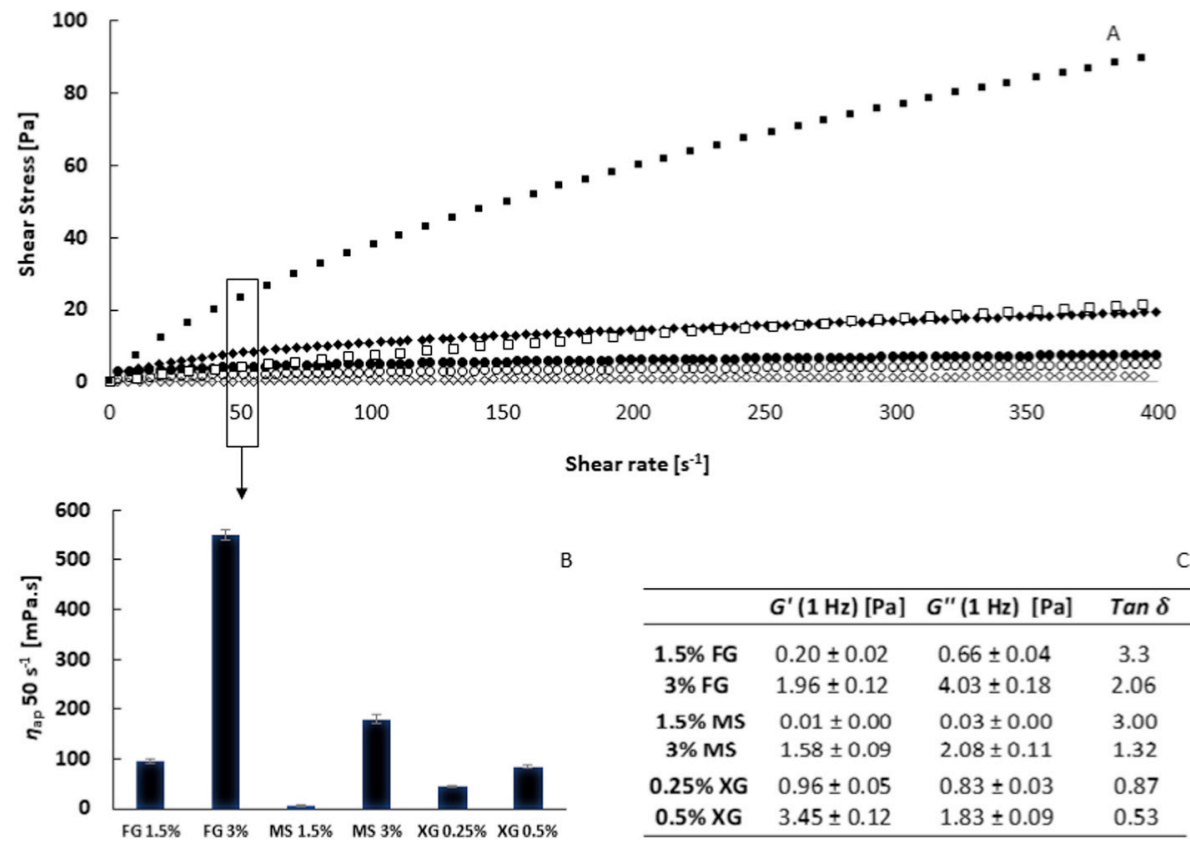

\begin{tabular}{cccc}
\hline & $G^{\prime}(1 \mathrm{~Hz})[\mathrm{Pa}]$ & $\mathbf{G}^{\prime \prime}(\mathbf{1 ~ H z})[\mathrm{Pa}]$ & $\operatorname{Tan} \delta$ \\
\hline $\mathbf{1 . 5} \% \mathrm{FG}$ & $0.20 \pm 0.02$ & $0.66 \pm 0.04$ & 3.3 \\
$\mathbf{3 \%} \mathrm{FG}$ & $1.96 \pm 0.12$ & $4.03 \pm 0.18$ & 2.06 \\
$\mathbf{1 . 5 \%} \mathrm{MS}$ & $0.01 \pm 0.00$ & $0.03 \pm 0.00$ & 3.00 \\
$\mathbf{3} \% \mathrm{MS}$ & $1.58 \pm 0.09$ & $2.08 \pm 0.11$ & 1.32 \\
$\mathbf{0 . 2 5} \%$ XG & $0.96 \pm 0.05$ & $0.83 \pm 0.03$ & 0.87 \\
$\mathbf{0 . 5} \%$ XG & $3.45 \pm 0.12$ & $1.83 \pm 0.09$ & 0.53 \\
\hline
\end{tabular}

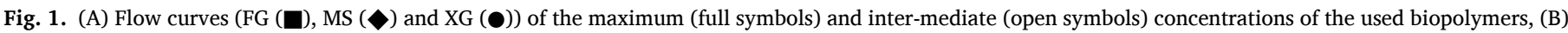
apparent viscosity at $50 \mathrm{~s}^{-1}$ (highlighted) and $(\mathrm{C})$ loss $\left(G^{\prime}\right)$ and storage $\left(G^{\prime \prime}\right)$ moduli and $\tan \delta$ at $1 \mathrm{~Hz}$.

thickener formulations in water on varied rheological properties were evaluated.

Apparent viscosity values at a fixed shear rate of $10 \mathrm{~s}^{-1}(\eta$ ap 10) (indicator of oral shear rate according to Cutler et al., 1983), $50 \mathrm{~s}^{-1}(\eta$ ap ${ }_{50}$ ) (used as a reference by the National Dysphagia Diet - NDD) and 400 $\mathrm{s}^{-1}(\eta$ ap 400) (representative value to which a liquid food is subjected during the swallowing process according to Meng et al., 2005); complex viscosity $\left(\eta^{*}\right)$ at $50 \mathrm{rad} \mathrm{s}^{-1}$ (angular frequency used for quantitative correlation with panel scores), flow index $n$ (as a shear-thinning indicator) and viscoelastic properties represented by elastic $\left(G^{\prime}\right)$ and viscous $\left(G^{\prime \prime}\right)$ moduli at a fixed frequency of $1 \mathrm{~Hz}$ and $\tan \delta$ were evaluated for the different formulations studied according to the CCRD.

\subsection{Colorimetry analysis}

The colour of thickened aqueous solutions was measured in triplicate using an Ultra Scan Vis 1043 (Hunter Lab, model Colour Quest II, USA) with reflectance mode, CIELab scale, D65 as illuminant and a $10^{\circ}$ observer angle as a reference system. Cylindrical coordinate $C^{*}$ (chroma) was evaluated, representing the colour intensity (Eq. (5)). Total colour difference $\left(\Delta E^{*}\right)$ (Eq. (6)) between the samples before and after thickeners addition were evaluated and calculated from $L^{*}$ (lightness), $a^{*}$ and $b^{*}$ (chromaticity parameters):

$C^{*}=\sqrt{\left(a^{* 2}+b^{* 2}\right)}$

$\Delta E^{*}=\sqrt{(\Delta L)^{2}+(\Delta a)^{2}+(\Delta b)^{2}}$

being $\Delta L=\left(L^{*}-L_{0} *\right), \Delta a=\left(a^{*}-a_{0} *\right)$ and $\Delta b=\left(b^{*}-b_{0} *\right)$, where, $L_{0} *$, $a_{0}{ }^{*}$ and $b_{0^{*}}$ are the initial colour values and $L^{*}, a^{*}$ and $b^{*}$ are the colour values of water matrix containing thickeners.

\subsection{Optical microscopy}

The morphology of single biopolymers (FG, MS and XG) was analysed using an optical microscope (Axio Scope.A1, Carl Zeiss, Germany). Images were taken using the "ZENLite" software package with a $10 \mathrm{x}$ objective lens.

\subsection{In vitro static digestion}

Formulations were selected to be subjected to in vitro static digestion analysis $(5 \mathrm{~mL})$ considering the three different levels of consistency assigned by NDD. A formulation without MS was also evaluated in order to observe the impact of this biopolymer on the final amount of glucose in relation to the studied gums. To compare these formulations with a commercial product based on MS, nectar and spoon like consistency systems were prepared (extreme available cases) according to the label of the product. Gastrointestinal in vitro digestion was performed according to the standardized static model by Minekus et al. (2014), at 37 ${ }^{\circ} \mathrm{C}$. Firstly, thickened samples were mixed with the simulated salivary fluid (SSF) for $2 \mathrm{~min}$ (oral phase). After that, simulated gastric fluid (SGF), porcine pepsin and calcium chloride were added to this mixture, and the $\mathrm{pH}$ was adjusted to 3 (gastric phase). The mixture was subjected to magnetic stirring at $100 \mathrm{rpm}$ during $2 \mathrm{~h}$. Finally, simulated intestinal fluid (SIF), pancreatin, calcium chloride and bile extract were added to the mixture with the same stirring velocity and temperature for $2 \mathrm{~h}$ more, at $\mathrm{pH} 7$ (intestinal phase). Adjustments of the corresponding $\mathrm{pH}$ values were performed during the whole timeframe of the experiment. Samples were removed at different times to analyse the glucose released.

\subsection{Glucose released}

Glucose concentration was measured using the Glucose Activity Assay Kit (LaborLAb, Brazil) according to the manufacturer's instructions and converted to amount of glucose released (mg). Sampling was carried out after oral phase simulation ( $2 \mathrm{~min}$ ), and during gastric phase (32, 62, 92 and $122 \mathrm{~min})$ and intestinal phase (152, 182, 212 and $242 \mathrm{~min}$ ) along the in vitro digestion. Each sample was analysed in duplicate.

\subsection{Statistical analyses}

The experimental design was evaluated using the "Protimiza Experimental Design" software $(\alpha=0.1)$. Colour data were subjected to analysis of variance (ANOVA) $(p<0.05)$ and the means were compared using Tukey's HSD test to examine if differences between formulations were significant $(\alpha=0.1)$. 

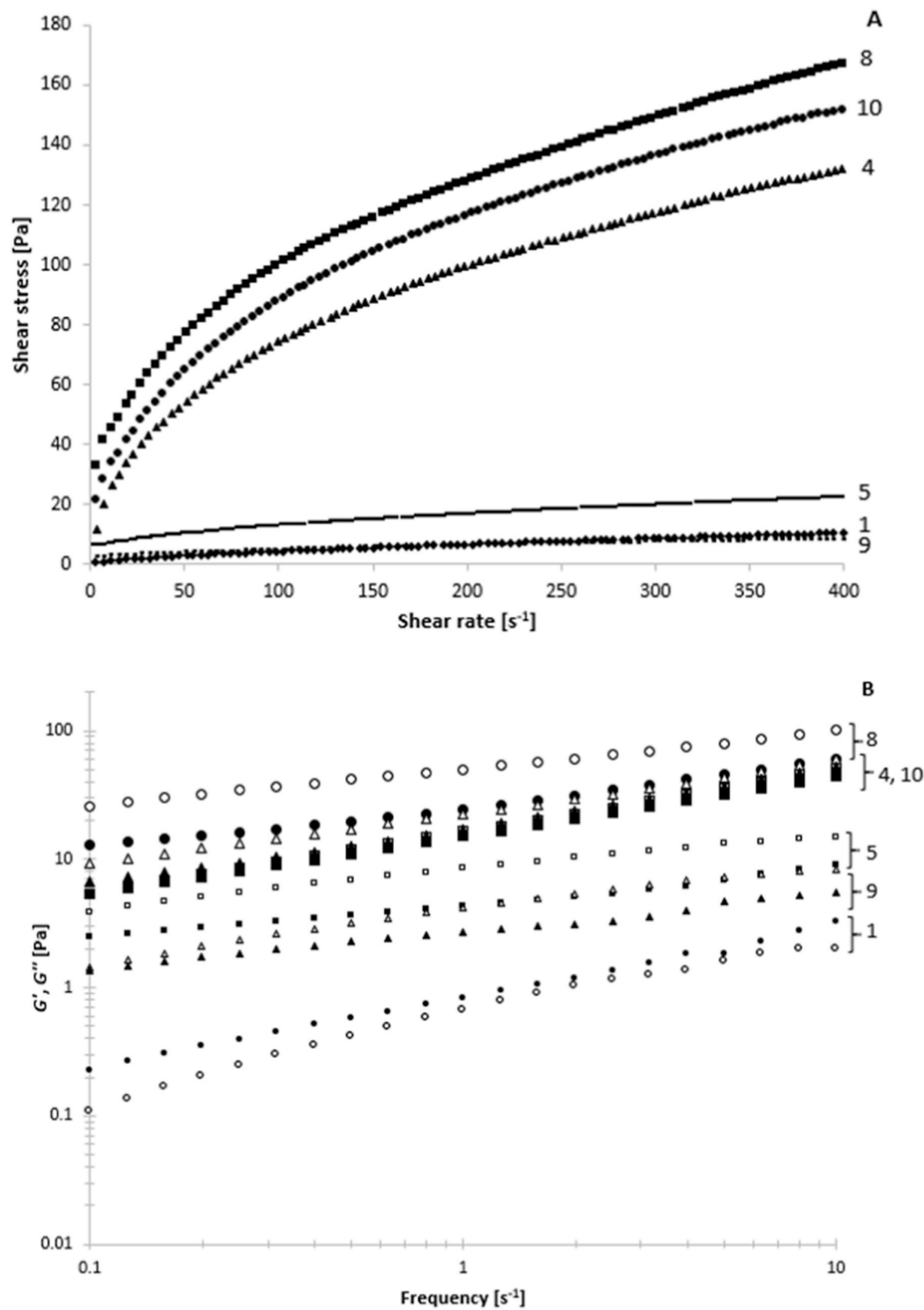

Fig. 2. Representative flow curves of thickener formulations dissolved in water (A). Highest viscosity: 4 ( $\mathbf{\Delta})(2.4 \% \mathrm{FG}, 2.4 \% \mathrm{MS}, 0.1 \% \mathrm{XG}), 8(\boldsymbol{\square})(2.4 \% \mathrm{FG}, 2.4 \%$ MS, 0.4\% XG) and $10(\bullet)(3 \%$ FG, 1.5\% MS, 0.25\% XG). Lowest viscosity: $1(\diamond)(0.6 \%$ FG, 0.6\% MS, 0.1\% XG), $5(-)(0.6 \%$ FG, 0.6\% MS, 0.4\% XG) and $9(\bullet)(1.5 \%$ MS, $0.25 \% \mathrm{XG}$ ). Elastic modulus (open symbols) and viscous modulus (closed symbols) as a function of frequency under isothermal $\left(25^{\circ} \mathrm{C}\right)$ conditions for the extreme viscosity of thickener solutions (Lowest viscosity (small symbols) (B): Formulation 1 ( $0.6 \%$ FG, 0.6\% MS, 0.1\% XG (•); Formulation 5: 0.6\% FG, 0.6\% MS, 0.4\% XG

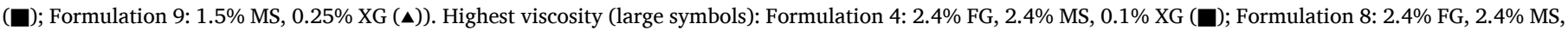
0.4\% XG (•); Formulation 10: 3\% FG, 1.5\% MS, 0.25\% XG (^)). 


\section{Results and discussion}

\subsection{Rheological properties}

All thickened liquid systems showed an increase in viscosity and did not show phase separation. This result indicates that these formulations could reduce the flow velocity from the mouth to the esophagus, thereby reducing/avoiding pulmonary aspiration caused by a dysfunctional airway protection.

\subsubsection{Biopolymer suspensions}

The rheological behaviour of aqueous solutions of individual biopolymers (FG, MS and XG) was studied within the concentration range (intermediate and maximum levels) used to prepare the thickened formulations (see section 3.1.2). Fig. 1A shows that all flow curves presented a non-Newtonian shear-thinning behaviour (although at the lowest concentration of MS $(0.75 \%)$, the Newtonian fluid model was well-fitted). A slight thixotropy was observed for the MS solutions, which is in accordance with Anastadiases et al. (2002). However, a shear time-independent behaviour was verified for FG and XG aqueous solutions, since all the three flow curves (up-down-up) overlapped with no signs of thixotropy. The apparent viscosity values at $50 \mathrm{~s}^{-1}$, used as a reference by the NDD to simulate the shear rate in the mouth, are shown in Fig. 1B. FG showed the highest viscosity $(551 \pm 10 \mathrm{mPa}$ ) followed by MS (180 $\pm 9 \mathrm{mPa} \mathrm{s})$ and XG ( $84 \pm 3 \mathrm{mPa} \mathrm{s})$ at the highest biopolymer concentration. On the other hand, at the intermediate concentration, MS (1.5\%) showed a very low apparent viscosity ( $6 \pm 1 \mathrm{mPa}$ s) even when compared to the $0.25 \%$ of XG concentration ( $45 \pm 2 \mathrm{mPa} \mathrm{s}$ ).

Viscoelastic properties concerning $G^{\prime}$ and $G^{\prime \prime}$ are presented in Fig. 1C. Regardless of biopolymers concentrations, the character of the solutions was not altered. FG and MS showed a prevailing viscous character (tan $\delta$ $>1$ ) whereas XG exhibited a predominated elastic behaviour (gel-like behaviour) ( $\tan \delta<1$ ). At similar concentration of MS and FG, $G^{\prime}$ and $G^{\prime \prime}$ values were higher for FG, but $G^{\prime}$ was lower than XG at smaller concentration $(0.5 \%)$. The prevailing viscous behaviour ( $\left.G^{\prime \prime}>G^{\prime}\right)$ of FG was also observed by Qian, Cui, Wu, and Goff (2012).

\subsubsection{Thickeners' formulations}

The flow curves of formulations that showed the highest viscosities (Formulations 4, 8 and 10, Table 1 in section 3.2) and the lowest viscosities (Formulations 1, 5 and 9, Table 1 in section 3.2) are represented in Fig. 2A. All thickeners solutions presented a shear time independent behaviour (without thixotropy or anti-thixotropy) and a shear thinning non-Newtonian behaviour, as $n$ values were lower than 1 , which implies a decrease in the apparent viscosity at increased shear rates. Chains of polymer molecules are arbitrarily positioned when the thickened solutions are at quiescent conditions but after application of shear forces, these molecules become aligned in the same flow direction. The hydrodynamic forces deform aggregates that eventually disrupt resulting in a reduction of viscosity in the shear thinning fluids (Farahmandfar, Asnaashari, Salahi, \& Rad, 2017; Koocheki, Reza-Taherian, \& Bostan, 2013).

Viscoelastic properties of these formulations were obtained from oscillatory rheology. The magnitudes of $G^{\prime}$ and $G^{\prime \prime}$ increased with the increase of frequency, indicating a slight frequency dependence. Higher $G^{\prime}$ and $G^{\prime \prime}$ values were obtained for thickeners with higher concentration of FG and MS (represented by the extreme cases in Fig. 2B). It is noteworthy that most of the formulations presented a prevailing elastic behaviour (Fig. 2B) within the frequency range $0.1-10 \mathrm{~Hz}\left(\mathrm{G}^{\prime}>\mathrm{G}^{\prime \prime}\right)$, except Formulation 1 (corresponding to the lowest concentration of each polymer) that exhibited a viscous behaviour (liquid-like). Therefore, although individually FG can present a prevailing viscous behaviour at the studied concentrations (Fig. 1), when this gum is dissolved together with XG, a stronger network with elastic behaviour was generated that increased its energy storage capacity. This ability was also observed in previous studies when the FG was mixed with proteins and gels (Hasanvand \& Rafe, 2018; Li, Li, Wang, Wu, \& Adhikari, 2012).

\subsection{CCRD analysis of rheological properties}

Apparent viscosity values at a fixed shear rate of $10 \mathrm{~s}^{-1}(\eta$ ap 10), 50 $\mathrm{s}^{-1}\left(\eta\right.$ ap 50) and $400 \mathrm{~s}^{-1}$ ( $\eta$ ap 400) (chosen as representative shear rates attained during the food mastication process), complex viscosity at 50 $\mathrm{rad} / \mathrm{s}\left(\eta{ }_{50}\right)$, flow index $(n)$, loss tangent $(\tan \delta)$, elastic $\left(G^{\prime}\right)$ and viscous $\left(G^{\prime \prime}\right)$ moduli at a fixed frequency of $1 \mathrm{~Hz}$ are shown in Table 1 for the different studied formulations according to CCRD.

In general, an increase of FG, MS and XG concentration caused an increase in the apparent viscosity and pseudoplasticity of the formulations. A higher content of total solids in solution can hinder the intermolecular movement induced by hydrodynamic forces, indicating a good interaction (or at least non-repulsive interactions) between the different components (Capitani et al., 2015). Viscosity values at a shear rate of $10 \mathrm{~s}^{-1}, 50 \mathrm{~s}^{-1}$ and $400 \mathrm{~s}^{-1}$ ranged from 105 to $4199 \mathrm{mPa} \mathrm{s}$, 57-1528 mPa s and 21-414 mPa s, respectively. Nectar-like (Formulations 1, 3, 5, 9, 11 and 13) and honey-like (Formulations 2, 4, 6, 7, 8, 10, $12,14,15,16$ and 17) consistency was achieved, although there were two formulations that approached the spoon-like consistency (Formulations 8 and 10), both containing high FG concentration.

Only Formulation 1 presented a viscosity close to the lowest recommended limit value by the NDD ( $50 \mathrm{mPa}$.s) considering the viscosity at a shear rate of $50 \mathrm{~s}^{-1}$, which could provide a quicker flow from the mouth to the larynx (O'Leary et al., 2010). The combination of biopolymers (FG, MS and XG) concentrations according to the experimental design could establish positive interactions in terms of the viscosity, since the quantity of total solids in some thickening formulations was low in comparison to individual biopolymers (Fig. 1) and commercial thickeners. Regarding to the studied formulations, it was observed that only $1.3 \%$ of total solids (Formulation 1) was necessary to achieve nectar-like consistency, while to reach values close to the spoon-thick category, $5.2 \%$ of total solids were required. Previous work have studied the rheological behaviour of commercial thickeners for dysphagia patients and observed that the XG-based thickener only required a thickener concentration of $0.88 \%(\mathrm{w} / \mathrm{v})$ in aqueous solutions (total solids) to obtain the nectar-like viscosity, although a thickener concentration above $11.5 \%(\mathrm{w} / \mathrm{v})$ was needed to reach a viscosity near from the category of spoon-thick (1345 $\pm 87 \mathrm{mPa}$ s). Similar content was necessary to observe high viscosity values in a commercial XG + MS-based thickener $(11 \% \mathrm{w} / \mathrm{v})$ but a higher amount of total solids was used $(1.5 \% \mathrm{w} / \mathrm{v})$ to obtain the nectar-like category. On the other hand, the commercial MS-based thickener needed a concentration close to $7 \%$ (w/v) to achieve spoon-like categorization (1691 $\pm 218 \mathrm{mPa}$ s), but $4 \%$ $(\mathrm{w} / \mathrm{v})$ of total solids had to be incorporated to reach the nectar-like behaviour (Hadde \& Chen, 2019). In other words, the biopolymers interaction in the present study demonstrates a similar efficiency to the best scenario with respect to commercial thickeners (XG- and XG + MSbased) to reach the nectar-like consistency, but a quite lower amount of total solids is necessary to achieve high consistency values.

Apparent viscosity is related to the flow velocity of a food bolus, but other rheological properties can complement information associated to sensory perception. Pseudoplasticity (represented by the flow index $(n)$ ) and complex viscosity at $50 \mathrm{rad} \mathrm{s}^{-1}\left(\eta *_{50}\right)$ are associated to sliminess in the mouth and perceived ease of swallowing (Richardson et al., 1989). The flow index of all samples, which indicates the extent of shear-thinning behaviour, ranged from 0.32 to 0.62 like in most high molecular weight polymers (Mandala, Savvas, \& Kostaropoulos, 2004). The lowest $n$ value belongs to the thickened formulation with the highest concentration of XG (Formulation 14). A more pronounced shear-thinning behaviour permits easier swallowing of the thickened liquids by dysphagic patients and also reducing organoleptic sliminess, resulting in a pleasant mouthfeel (Jo et al., 2018). On the other hand, the highest $n$ value was obtained with Formulation 1, the polysaccharide mixture with the lowest biopolymer concentrations, and Formulation 
Table 2

Percentage of explained variance $\left(\mathrm{R}^{2}\right)$, calculated $\mathrm{F}\left(\mathrm{F}_{\text {calc }}\right) /$ tabulated $\mathrm{F}\left(\mathrm{F}_{\mathrm{tab}}\right)$ for the responses apparent viscosity at different shear rates $\left(\eta\right.$ ap 10, $\eta$ ap 50, and $\eta_{\text {ap }}$ 400 (mPa.s)), complex viscosity ( $\eta^{*}{ }_{50}$ (Pa.s)), flow index $(n)$ and viscoelastic properties ( $G^{\prime}$ and $G^{\prime \prime}(\mathrm{Pa})$ ), by analysis of variance (ANOVA). Statistically significant models have $\mathrm{F}_{\text {calc }} / \mathrm{F}_{\text {tab }}$ values greater than 1 .

\begin{tabular}{|c|c|c|}
\hline Response equations & $\mathrm{R}^{2}$ & $\begin{array}{l}\mathrm{F}_{\text {calc }} / \\
\mathrm{F}_{\text {tab }}\end{array}$ \\
\hline 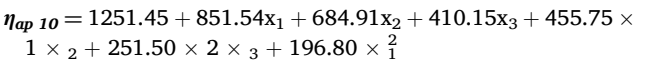 & 0.96 & 14.63 \\
\hline $\begin{array}{l}\eta_{a p 5 o}=496.72+341.94 \mathrm{x}_{1}+230.50 \mathrm{x}_{2}+129.01 \mathrm{x}_{3}+158.86 \times \\
1 \times{ }_{2}+66.58 \times 2 \times{ }_{3}+70.45 \times{ }_{1}\end{array}$ & 0.98 & 30.16 \\
\hline $\begin{array}{l}\eta_{\text {ap }} 400=143.82+112.11 \mathrm{x}_{1}+46.97 \mathrm{x}_{2}+33.32 \mathrm{x}_{3}+27.81 \times 1 \times 1 \times \\
\quad 2+11.29 \times 1 \times 3+23.36 \times{ }_{1}^{2}+10.44 \times \frac{2}{2}\end{array}$ & 0.99 & 49.56 \\
\hline$n=0.47-0.06 x_{2}-0.05 x_{3}+0.03 \times 1 \times{ }_{3}-0.03 \times{ }_{1}^{2}$ & 0.80 & 4.80 \\
\hline $\begin{array}{l}G^{\prime}{ }_{1 \mathrm{~Hz}}=12.50+6.05 \mathrm{x}_{1}+9.89 \mathrm{x}_{2}+8.11 \mathrm{x}_{3}+5.10 \times 1 \times_{2}+7.01 \\
\quad \times 2 \times 3+3.07 \times \frac{2}{2}\end{array}$ & 0.92 & 7.48 \\
\hline $\begin{array}{l}G^{\prime \prime} 1 \mathrm{~Hz}=6.52+4.08 \mathrm{x}_{1}+4.77 \mathrm{x}_{2}+2.69 \mathrm{x}_{3}+1.89 \times 1 \times{ }_{2}+1.61 \\
\quad \times 2 \times{ }_{3}+1.13 \times{ }_{1}^{2}+1.71 \times \frac{2}{2}\end{array}$ & 0.97 & 16.57 \\
\hline $\begin{array}{l}\eta^{*} 50=2.20+0.80 \mathrm{x}_{1}+1.73 \mathrm{x}_{2}+1.18 \mathrm{x}_{3}+0.66 \times 1 \times 2+0.97 \times \\
2 \times{ }_{3}+0.39 \times{ }_{2}\end{array}$ & 0.96 & 13.11 \\
\hline
\end{tabular}

\section{3, a thickened solution without XG.}

Tan $\delta$ smaller than the unity and high $G^{\prime}$ values have been suggested as a rheological criterion for safe-swallow (Jo et al., 2018; Steffe, 1996). As shown in Table 1, most of the samples exhibited a weak gel-like behaviour, including the formulations without FG (Formulation 9) and

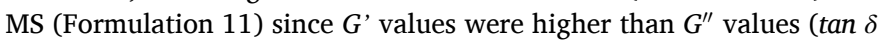
was lower than 1) regardless the frequency (between 0.1 and $10 \mathrm{~Hz}$ ). Formulation with the highest concentration of XG (Formulation 14) showed the lowest value of $\tan \delta(0.41)$, while the formulation without XG (Formulation 13) showed the highest $\tan \delta$ value (2.58) or prevailing viscous behaviour, indicating a potential difficulty in the dysphagic swallowing process for formulations without xanthan addition. Considering this assumption, it can be concluded that interactions between XG and MS/FG could even more to contribute positively to the elastic properties and consequently on swallowing process.

\subsubsection{Multivariate analysis: mathematical modelling}

Mathematical models were fitted to the experimental data, to allow a more consistent description of the effect of the thickener's combinations on the rheological behaviour of the formulations. Thus, different concentration of FG $\left(x_{1}\right)$, MS $\left(x_{2}\right)$ and XG $\left(x_{3}\right)$ were analysed to evaluate their effect on the rheological properties ( $\eta_{\text {ap }} 10, \eta_{\text {ap }} 50, \eta_{\text {ap }} 400, \eta^{*}{ }_{50}, n$, $G^{\prime}$ and $G^{\prime \prime}$ ) using a CCRD (Table 1). All properties shown in Table 2 presented a significant $(p<0.1)$ non-linear fitting as a function of the variables. Only statistically significant $(p<0.1)$ coefficients were maintained and the validity of each model was verified through Analysis of Variance (ANOVA). The coefficient of determination $\left(\mathrm{R}^{2}\right)$ and the Ftest $\left(\mathrm{F}_{\text {calc }} / \mathrm{F}_{\text {tab }}>1\right)$ showed that the models were reliable. It should be noted that central points (Formulations 15, 16 and 17) showed repeatability for all parameters (Table 1) and, therefore, the study can be considered valid.

The viscosity was positively and significantly influenced by all biopolymers, regardless of the applied shear rate in the following order: FG $>$ MS $>$ XG. Fig. 3 shows the values of the apparent viscosity at a shear rate of $50 \mathrm{~s}^{-1}$ obtained experimentally and predicted by the model as a function of the concentration of FG, MS and XG. MS presented a positive interaction with FG (Fig. 3B) and also with XG at lowest shear rates, while FG-XG interaction was evident only at $400 \mathrm{~s}^{-1}$. XG presented a strong relative influence on viscosity (i.e., when such influence is considered per gram of biopolymer used) when compared to the other biopolymers. However, due to the relatively low XG concentrations used, the corresponding absolute influence on viscosity was minor. Xanthan can form high-viscosity solutions, especially at low shear rates, due to XG aggregates formed through hydrogen bonding and polymer entanglements (Russ, Zielbauer, Ghebremedhin, \& Vilgis, 2016). At high shear rates, the viscosity of XG solutions decreased due to the disentanglement of the polymer network and the partial alignment of the individual macromolecules in the direction of the shear flow (Song, Kim, \& Chang, 2006). Moreover, mixed gums systems (XG-MS or XG-other gums) showed higher viscosity than aqueous dispersions of MS and $\mathrm{XG}$, which may be related to synergistic interactions leading to larger shear forces necessary to apply on the mixed systems (Mandala, Palogou \& Kostaropoulos, 2002).

Despite the low viscosity and pseudoplasticity (Fig. 1) of MS aqueous solutions, this biopolymer showed a strong influence on both parameters when incorporated in solutions together with XG and FG (Table 2). A potential synergy between MS and XG was observed from the decrease of
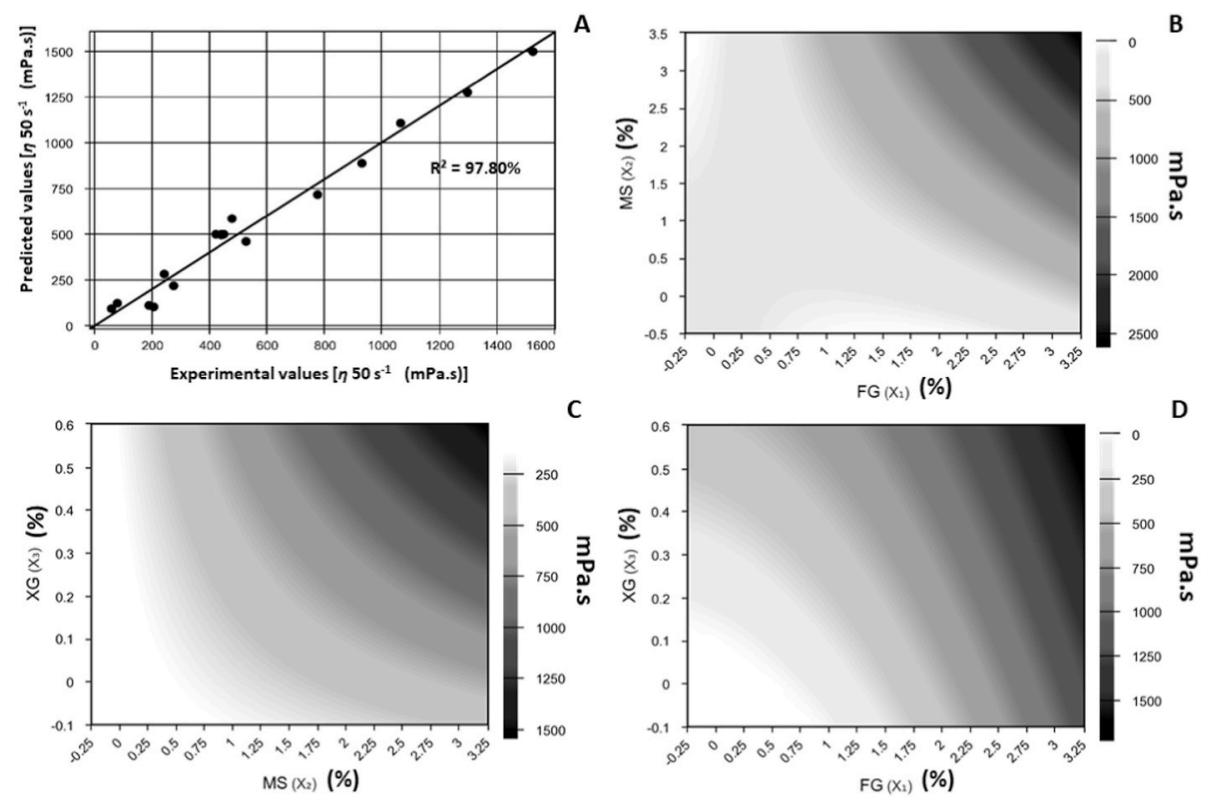

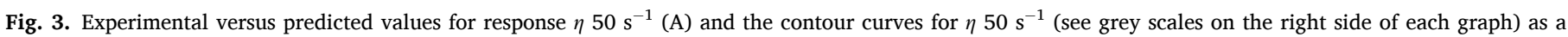

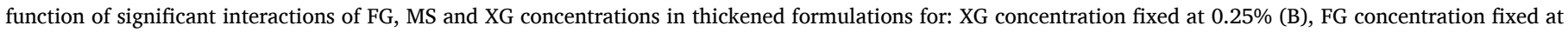
$1.5 \%(C)$ and MS concentration fixed at $1.5 \%$ (D). 
Table 3

Predicted and experimental viscosity at a shear rate of $50 \mathrm{~s}^{-1}$ obtained from new formulations for validation of the previous results.

\begin{tabular}{|c|c|c|c|c|c|c|c|}
\hline \multirow[b]{2}{*}{ Matrix } & \multirow[b]{2}{*}{ Categorization } & \multicolumn{3}{|c|}{ Formulation (\%) } & \multirow{2}{*}{$\begin{array}{l}\text { Experimental (mPa.s) } \\
\eta_{\text {ap } 50}\end{array}$} & \multirow{2}{*}{$\begin{array}{l}\text { Predicted (mPa.s) } \\
\eta_{\text {ap } 50}\end{array}$} & \multirow[t]{2}{*}{ Relative Error (\%) } \\
\hline & & FG & MS & $X G$ & & & \\
\hline & Nectar $^{\mathrm{a}}$ & 1.5 & 0.15 & 0.1 & $121 \pm 8$ & $124 \pm 62$ & 2.4 \\
\hline \multirow[t]{2}{*}{ Water } & Honey $^{\mathrm{b}}$ & 1.5 & 1.5 & 0.25 & $455 \pm 18$ & $498 \pm 26$ & 8.6 \\
\hline & Spoon $^{c}$ & 2.5 & 3 & 0.25 & $2023 \pm 40$ & $1860 \pm 95$ & 8.8 \\
\hline
\end{tabular}

\footnotetext{
a $51-350 \mathrm{cP}^{*}$.

b $351-1750 \mathrm{cP}^{*}$.

c $>1750 \mathrm{cP}^{*}$.
}

the flow index (Kim \& Yoo, 2006; Hadde \& Chen, 2019), which can have resulted in the commercialization of products containing both biopolymers for dysphagia patients. In addition, Szczesniak and Farkas (1963) reported that high molecular weight polysaccharides with a high $n$ value lead to a slimy feel in the mouth, showing that XG addition (that decreases $n$ value) can favour sensory acceptance of thickeners. The $n$ value of FG varied between 0.83 and 0.58 for the concentrations of $0.75 \%$ and $3 \%(\mathrm{w} / \mathrm{w})$, respectively, values which were substantially reduced with the addition of MS and XG (Table 1) (Vieira et al., 2019). Therefore, an equilibrated addition of FG, MS and XG can hinder an organoleptic sliminess feeling when consuming the thickened liquids (Vieira et al., 2020).

Dynamic rheological analysis of thickened liquids has shown that viscoelastic properties $\left(G^{\prime}, G^{\prime \prime}\right)$ were positively influenced by all biopolymers (Table 2). Elastic properties, represented by the $G^{\prime}$ value, are associated to the bolus formation, helping in a safe and easy swallowing (Jo et al., 2018). Fig. 1 shows that FG exhibited a prevailing viscous rather than elastic behaviour up to a concentration of $3 \% \mathrm{w} / \mathrm{w}$. However, according to Table 2, this biopolymer showed a significant positive influence on the elastic properties and synergistic interaction with MS in aqueous solution. MS also showed interactions with XG (Table 2), since the elastic modulus of the mixed system was higher than the pure additive contribution for both starch and xanthan (Abdulmola, Hember,
Richardson, \& Morris, 1996, Kim \& Yoo, 2006; Russ et al., 2016). However, XG alone induces an overall increase in elastic behaviour even at low concentrations (Fig. 1) (Choi, Mitchell, Gaddipatia, Hill, \& Wolf, 2014; Choi \& Yoo, 2009; Choppe, Puaud, Nicolai, \& Benyahia, 2010), since this gum is generally capable of establishing strong intermolecular associations (Heyman, De Vos, Van der Meerer \& Dewettinck, 2014). XG could surround starch granules forming a binder thin film and thus forming a stronger network (Mandala \& Palogou, 2003). These facts may explain why XG impact on elastic properties $\left(G^{\prime}\right)$ was higher than FG and close to MS, despite of the studied XG concentration range being lower than FG and MS.

Complex viscosity $\eta^{*}{ }_{50}$ can also give information about the sensory consistency, such as perceived thickness, of viscoelastic weak gels, which is the case of the studied thickened formulations (Richardson et al., 1989). The increase in MS concentration was the greatest contribution to complex viscosity, followed by that of XG. Indeed, the highest value of $\eta^{*} 50$ was usually observed for formulations with higher MS concentrations. Formulations with higher $\eta{ }^{*} 50$ represent structured gels, promoting a safer and pleasant swallowing, whereas those with low $\eta{ }^{*}$ 50 present a more fluid-like consistency that are more prone to result in aspiration during consumption (He et al., 2016; Veiga, Cunha, Viotto $\&$ Petenate, 2000; Vieira et al., 2020).

From the response surfaces (not shown) and contour curves for
FG

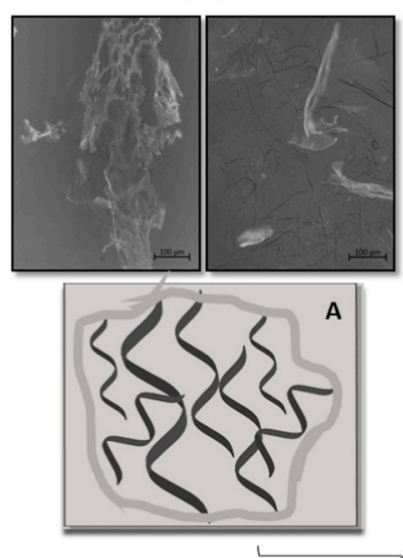

MS

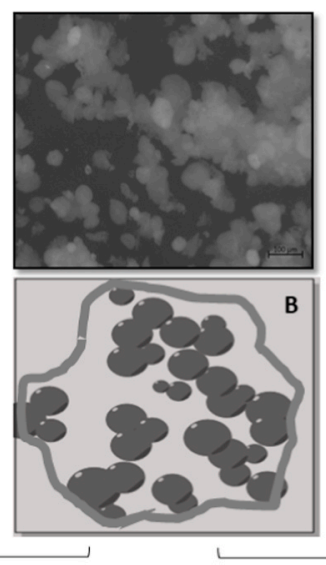

XG

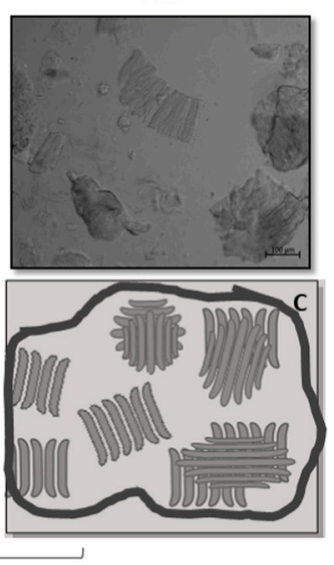

MS+FG

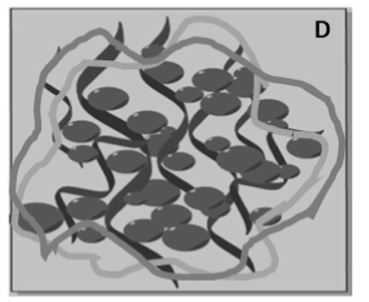

MS+XG

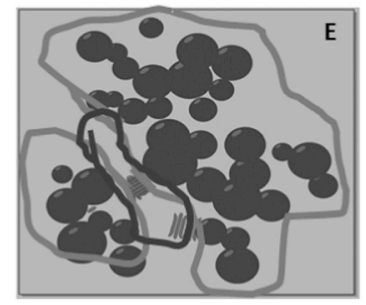

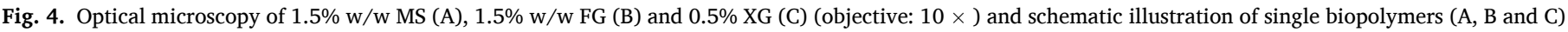
and proposed structure for the corresponding mixtures (D and $E$ ). 
Table 4

$L^{\mathrm{a}}, C^{\mathrm{a}}$ and $\Delta E^{\mathrm{a}}$ values of control (C - water) and thickened formulations (TF).

\begin{tabular}{|c|c|c|c|c|c|c|}
\hline $\mathrm{TF}$ & $\mathrm{FG}\left(\mathrm{x}_{1}\right)$ & $\operatorname{MS}\left(\mathrm{x}_{2}\right)$ & $X G\left(x_{3}\right)$ & $\mathrm{L}^{\mathrm{a}}$ & $\mathrm{C}^{\mathrm{a}}$ & $\Delta \mathrm{E}^{\mathrm{a}}$ \\
\hline & $(\%)$ & $(\%)$ & (\%) & & & \\
\hline C & - & - & - & $\begin{array}{l}27.9 \pm \\
0.2^{\mathrm{j}}\end{array}$ & $\begin{array}{l}0.6 \pm \\
0.0^{g}\end{array}$ & - \\
\hline 1 & $-1(0.6)^{a}$ & $-1(0.6)$ & $-1(0.1)$ & $\begin{array}{l}30.0 \pm \\
0.1^{\mathrm{h}}\end{array}$ & $\begin{array}{l}0.5 \pm \\
0.0^{g}\end{array}$ & $2.5 \pm 0.1$ \\
\hline 2 & $1(2.4)$ & $-1(0.6)$ & $-1(0.1)$ & $\begin{array}{l}30.6 \pm \\
0.1^{g}\end{array}$ & $\begin{array}{l}0.6 \pm \\
0.1^{g}\end{array}$ & $2.8 \pm 0.3$ \\
\hline 3 & $-1(0.6)$ & $1(2.4)$ & $-1(0.1)$ & $\begin{array}{l}31.8 \pm \\
0.1^{\mathrm{f}}\end{array}$ & $\begin{array}{l}1.3 \pm \\
0.0^{\mathrm{e}}\end{array}$ & $4.4 \pm 0.2$ \\
\hline 4 & $1(2.4)$ & $1(2.4)$ & $-1(0.1)$ & $\begin{array}{l}37.2 \pm \\
0.8^{\mathrm{d}}\end{array}$ & $\begin{array}{l}2.0 \pm \\
0.0^{\mathrm{c}}\end{array}$ & $9.4 \pm 0.8$ \\
\hline 5 & $-1(0.6)$ & $-1(0.6)$ & $1(0.4)$ & $\begin{array}{l}31.4 \pm \\
0.2^{\mathrm{f}}\end{array}$ & $\begin{array}{l}1.4 \pm \\
0.1^{\mathrm{e}}\end{array}$ & $4.1 \pm 0.1$ \\
\hline 6 & $1(2.4)$ & $-1(0.6)$ & $1(0.4)$ & $\begin{array}{l}39.9 \pm \\
0.3^{\mathrm{b}}\end{array}$ & $\begin{array}{l}2.8 \pm \\
0.1^{\mathrm{b}}\end{array}$ & $\begin{array}{l}12.2 \pm \\
0.7\end{array}$ \\
\hline 7 & $-1(0.6)$ & $1(2.4)$ & $1(0.4)$ & $\begin{array}{l}35.1 \pm \\
0.3^{\mathrm{e}}\end{array}$ & $\begin{array}{l}0.8 \pm \\
0.1^{\mathrm{f}}\end{array}$ & $7.3 \pm 0.2$ \\
\hline 8 & $1(2.4)$ & $1(2.4)$ & $1(0.4)$ & $\begin{array}{l}42.1 \pm \\
0.2^{\mathrm{a}}\end{array}$ & $\begin{array}{l}2.7^{ \pm} \\
0.1^{\mathrm{b}}\end{array}$ & $\begin{array}{l}14.3 \pm \\
0.9\end{array}$ \\
\hline 9 & $\begin{array}{l}-1.68 \\
(0)\end{array}$ & $0(1.5)$ & $0(0.25)$ & $\begin{array}{l}29.0 \pm \\
0.1^{\mathrm{i}}\end{array}$ & $\begin{array}{l}1.7 \pm \\
0.1^{\mathrm{d}}\end{array}$ & $2.6 \pm 0.1$ \\
\hline 10 & $1.68(3)$ & $0(1.5)$ & $0(0.25)$ & $\begin{array}{l}41.2 \pm \\
0.2^{\mathrm{b}}\end{array}$ & $\begin{array}{l}3.4 \pm \\
0.0^{\mathrm{a}}\end{array}$ & $\begin{array}{l}13.6 \pm \\
0.3\end{array}$ \\
\hline 11 & $0(1.5)$ & $\begin{array}{l}-1.68 \\
(0)\end{array}$ & $0(0.25)$ & $\begin{array}{l}31.7 \pm \\
0.2^{\mathrm{f}}\end{array}$ & $\begin{array}{l}0.4 \pm \\
0.0^{\mathrm{h}}\end{array}$ & $3.9 \pm 0.3$ \\
\hline 12 & $0(1.5)$ & $1.68(3)$ & $0(0.25)$ & $\begin{array}{l}38.7 \pm \\
0.2^{\mathrm{c}}\end{array}$ & $\begin{array}{l}1.4 \pm \\
0.1^{\mathrm{e}}\end{array}$ & $\begin{array}{l}10.8 \pm \\
0.4\end{array}$ \\
\hline 13 & $0(1.5)$ & $0(1.5)$ & $-1.68(0)$ & $\begin{array}{l}28.0 \pm \\
0.2^{\mathrm{j}}\end{array}$ & $\begin{array}{l}1.1 \pm \\
0.2^{\mathrm{e}}\end{array}$ & $1.8 \pm 0.1$ \\
\hline 14 & $0(1.5)$ & 0 (1.5) & $\begin{array}{l}1.68 \\
(0.5)\end{array}$ & $\begin{array}{l}36.9 \pm \\
0.2^{\mathrm{d}}\end{array}$ & $\begin{array}{l}0.6 \pm \\
0.0^{g}\end{array}$ & $9.1 \pm 0.1$ \\
\hline 15 & $0(1.5)$ & $0(1.5)$ & $0(0.25)$ & $\begin{array}{l}35.6 \pm \\
0.5^{\mathrm{e}^{-}}\end{array}$ & $\begin{array}{l}0.6 \pm \\
0.0^{g}\end{array}$ & $7.7 \pm 0.4$ \\
\hline
\end{tabular}

a-k Different letters in the same column correspond to statistically different samples for a $95 \%$ confidence level.

a Coded and uncoded values (in parenthesis) representing biopolymers concentration.

viscosity at $50 \mathrm{~s}^{-1}$ (Fig. 3), three formulations were produced to confirm and validate the mathematical model, aiming at representing each categorization published by NDD (nectar-like, honey-like and spoon thick). Thus, to validate the predictions obtained with the mathematical models for the viscosity at $50 \mathrm{~s}^{-1}$, new formulations within the studied concentration range were prepared, in triplicate, as shown in Table 3. Validation of the viscosity response at $50 \mathrm{~s}^{-1}$ was selected for presentation to observe if the categorization was respected, since it currently represents the most relevant data for patient's safety.

Experimental values of viscosity agreed with the model's prediction within the representative range of the categorization established by NDD. At lower viscosity, the experimental values were within the standard deviations of predicted values. However, for the categorization of spoon thick, although the viscosity presented experimental values above the expected by the model, they were still acceptable (relative error lower than 9\%).

\subsection{Optical microscopy imaging}

The structures proposed to describe the improvement of the viscoelastic and shear thinning properties of the thickened formulations composed of MS + FG and MS + XG mixtures were formulated based on the single biopolymers' images (Fig. 4). The mixture between MS and FG can form a well-mixed structure with both biopolymers. MS presented a network of embedded granules (Fig. 4B) promoting an intermolecular physical interaction (Fig. 4D) with the FG flexible polymer chains (Fig. 4A). Our hypothesis is that FG molecules are not only adsorbed on the MS granules, but also trapped and intertwined with them. Thus, the presence of a random coil polymer like FG probably increases the number of interactions between molecules, forming a more
Table 5

Regression coefficients of the mathematical models generated (coded model) for the colour parameters $\left(L^{*}, C^{*}\right.$ and $\left.\Delta E^{*}\right)$ of biopolymers dispersed in water, with the respective coefficient of determination $\left(\mathrm{R}^{2}\right)$. Statistically significant models have $\mathrm{F}_{\text {calc }} / \mathrm{F}_{\text {tab }}$ values greater than 1 .

\begin{tabular}{lll}
\hline Response equations & $\mathrm{R}^{2}$ & $\begin{array}{l}\mathrm{F}_{\text {calc }} / \\
\mathrm{F}_{\text {tab }}\end{array}$ \\
\hline $\boldsymbol{L}^{*}=35.49+3.08 \mathrm{x}_{1}+1.91 \mathrm{x}_{2}+2.48 \mathrm{x}_{3}+1.19 \times 1 \times{ }_{3}-0.96 \times 3_{3}^{2}$ & 0.96 & 19.00 \\
$\boldsymbol{C}^{*}=0.8+0.51 \mathrm{x}_{1}+0.23 \mathrm{x}_{2}+0.31 \times 1 \times{ }_{3}-0.36 \times 2 \times{ }_{3}+0.65$ & 0.86 & 5.21 \\
$\quad \times{ }_{1}^{2}$ & & \\
$\Delta \boldsymbol{E}^{*}=7.78+2.85 \mathrm{x}_{1}+1.86 \mathrm{x}_{2}+1.23 \times 1 \times{ }_{3}-0.77 \times{ }_{1}^{2}$ & 0.96 & 20.58 \\
\hline
\end{tabular}

homogeneous three-dimensional physical network in thickened formulations (Russ et al., 2016). XG is also able to associate with the MS granule surface (Chaisawang \& Suphantharika, 2006; Heyman, De Vos, Depypere, Van der Meeren, \& Dewettinck, 2014), although a micro-phase separation between XG and tapioca starch has previously been observed (Russ et al., 2016). According to the scheme proposed in Fig. $4 \mathrm{E}$, an interaction between the two polymers can occur on the external surface of the structure. A similar interaction was observed between pregelatinized starch and i-carrageenan (Russ et al., 2014). These results suggest that XG (present in the rod-like conformation) may be associated with swollen MS granules from non-electrostatic interactions (Heyman et al., 2014), forming a more heterogeneous network. Therefore, the mobility and diffusion of XG and FG molecules lead to the formation of a stronger physical network when mixed with MS, influencing the rheological behaviour that results in a predominance of elastic over viscous behaviour (weak gel) (Chaisawang \& Suphantharika, 2006; Heyman et al., 2014).

\subsection{Colorimetric analyses}

The colour of the product plays a significant role on its acceptability for consumers. Colour parameters $\left(L^{*}, C^{*}\right.$ and $\left.\Delta E^{*}\right)$ of thickened solutions were analysed and results are presented in Table 4. In general, thickeners addition modified the colour parameters observed from a colorimeter, although the visual appearance only showed greater opacity and a slight colour change.

Reflectance spectrophotometry indicated a change in the colour of the samples mainly due to a significant variation $(p<0.05)$ of the lightness $\left(L^{*}\right)$ values for the different formulations. For example, $L^{*}$ value was $27.9 \pm 0.2$ for the control (water) and in formulation 8 this value increased to $42.1 \pm 0.2$ (extreme case). As relevant changes were observed in colour parameters, mathematical models were generated (Table 5) to analyse the impact of the biopolymer's concentration on this matrix. The colour parameters were mainly influenced by the FG concentration followed by MS and XG. FG exerted a significant $(p<0.05)$ effect on $L^{*}$ and chroma ( $C^{*}$ ) (Tables 4 and 5); the latter is associated to colour saturation that is indicating a higher colour intensity as can be seen in Formulations 4, 6, 8 and 10 (higher FG concentration). This fact was confirmed by $\Delta E^{*}$ values, since they were quite high (always $\Delta E^{*}>$ 8) for these formulations, concluding that these thickeners formulations can present colour alteration compared to the control matrix (Olivas \& Barbosa-Cánovas, 2005). Formulations 1, 2, 3, 5, 7, 9, 11, 13 and 15 presented a $\Delta E^{*}$ designated as "very good" according to the American Society for Testing and Materials, since $\Delta E^{*}$ were always below 8 , confirming the small colour differences observed directly by the eye. XG presented reduced influence on colour properties, showing only interaction effect with FG when evaluating colour difference with the control.

In sum, FG was the component that showed the greatest influence on $L^{*}$ and $C^{*}$ parameters, and this was mirrored in the impact that its concentration provokes on the colour modification, since the $\Delta E^{*}$ was more influenced by this biopolymer than by MS and XG. Thus, this biopolymer is fundamental to rheological properties, but it should be added in moderate concentration to avoid colour changes. 


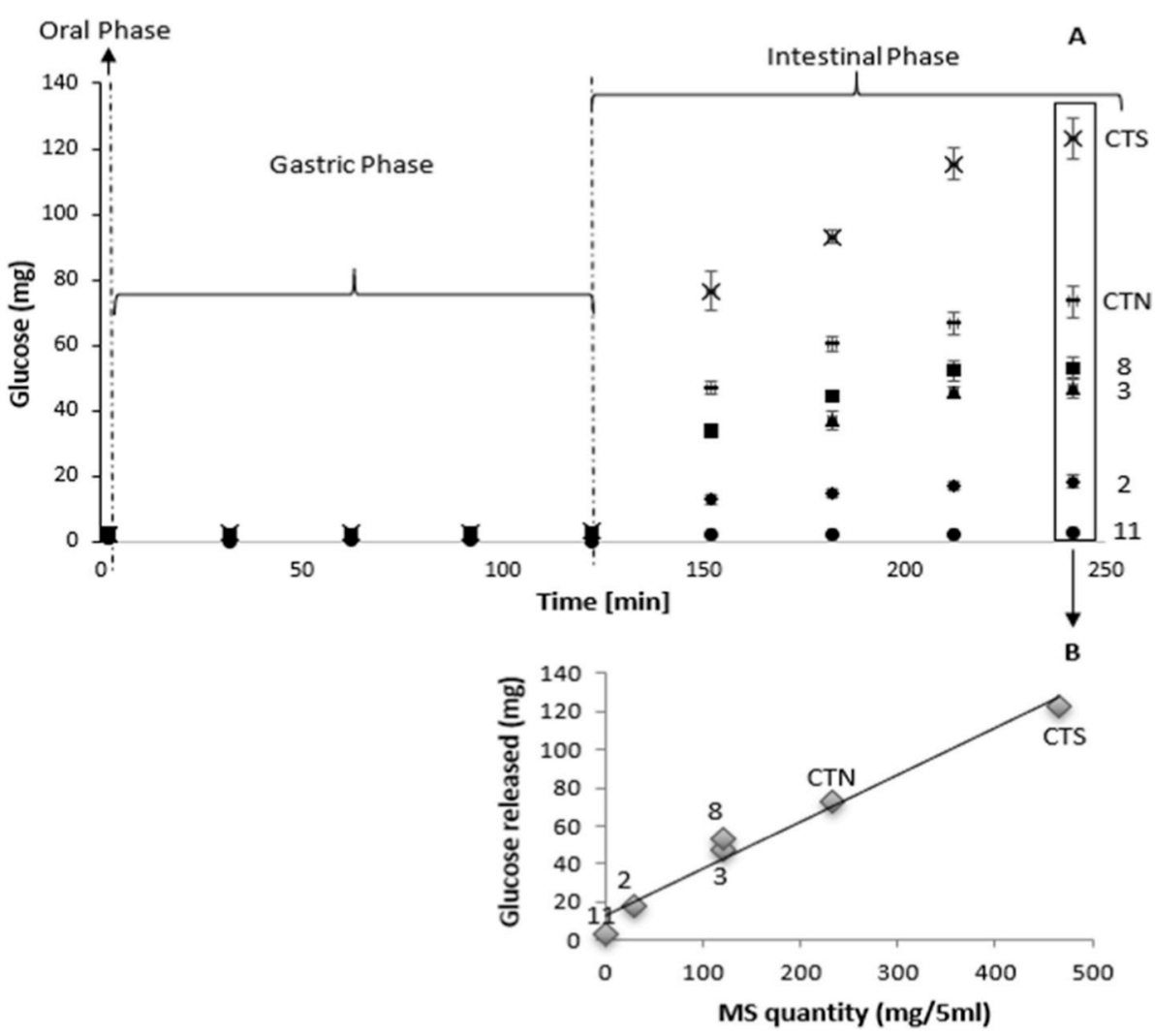

Fig. 5. Amount of glucose released during the in vitro digestibility (A) mount of Total solids (B) and MS quantity (C) to $5 \mathrm{ml}$ of thickened solutions versus glucose released during the in vitro digestibility (B) of the different thickened formulations: Commercial thickener - Spoon-thick consistency (CTS) $(\times)$; Commercial thickener - nectar consistency (CTN) (-); Formulations 2 (2.4\% FG, 0.6\% MS, 0.1\% XG) ( ); 3 (0.6\% FG, 2.4\% MS, 0.1\% XG) (ם); 8 (2.4\% FG, 2.4\% MS, $0.4 \%$ XG) (ム); 11 (1.5\% FG, 0.25\% XG) (•). It was considered the different phases: oral (0-2 min), gastric (2-122 $\mathrm{min})$ and intestinal (122-242 $\mathrm{min})$.

\subsection{Glucose response}

Static in vitro digestion was performed to quantify the amount of glucose released from the different thickener formulations, which is shown in Fig. 5. At the end of the in vitro digestion process, higher glucose levels were observed for both systems represented by the commercial formulations, CTS (123.25 $\pm 6.18 \mathrm{mg})$ with a spoon-thick consistency and CTN $(73.35 \pm 4.88 \mathrm{mg})$ with a nectar-like consistency, since these were the formulations containing the highest starch content (465 and $233 \mathrm{mg}$ of starch to $5 \mathrm{ml}$ of sample, respectively). Formulations 3 $(46.89 \pm 2.30 \mathrm{mg})$ and $8(53.26 \pm 3.25 \mathrm{mg})$, both with $2.4 \%$ of MS, presented similar values of released glucose at the end of the in vitro digestion, despite the FG concentration was considerably higher in the formulation 8. Moreover, viscosity of the formulation 3 (206 mPa.s) was quite lower than the formulation 8 (1528 mPa.s), which allows to conclude that a spoon-thick consistency could be achieved with a reduced release/absorption of glucose. Or a nectar-like consistency could be produced with even lower released glucose content if the combination of biopolymers content considered a reduction of starch content (Fig. 5B).

These results may be related to the following facts: a) the glucose present in the FG chain was not sufficient to increase the glucose released or b) FG incorporated in Formulation 8 results in a slower glucose release, since the FG dietary fibres may encapsulate starch resulting in a slowly available glucose (Englyst, Englyst, Hudson, Cole, \& Cummings, 1999). The former consideration (option a) is quite reasonable since Formulation 11 (without addition of MS) showed a very low glucose content $(2.90 \pm 0.34 \mathrm{mg})$, confirming that, glucose released from FG and XG was significantly lower than the MS. In addition, the formulation with honey-like consistency (Formulation 2) and intermediate MS concentration ( $0.6 \% \mathrm{MS}$ ) showed the lowest amount of glucose released $(18.43 \pm 1.80 \mathrm{mg})$ regarding to the other formulations with MS (with $2.4 \% \mathrm{MS}$ ). This result also emphasizes that the glucose content released is mostly from MS. These facts demonstrates, again, the importance of the interactions between the biopolymers and their influence on physical and nutritional properties, since the increase of FG concentration (and MS concentration decrease, 2.4\%-0.6\%) increased the consistency/viscosity from nectar (Formulation 3-206 mPa s) to honey-like (Formulation 2-529 $\mathrm{mPa}$ ) with a significant decrease of glucose released because FG is richer in fibres, as can be observed in Fig. 5B (Moczkowska, Karp, Niu \& Kurek, 2019). This result suggests that FG can be an option for thickeners formulations with a good glucose response, and may partially replace starch, depending on the desired viscosity levels, without compromising disphagic patient's safety.

\section{Conclusions}

A relation between functionality/rheological properties of thickeners and their benefits in terms of health, increasing fibres and phenolic content and decreasing glucose absorption, was considered regarding the incorporation of flaxseed gum (FG) in thickening formulations for dysphagia patients. FG showed the greatest positive influence on viscosity followed by modified starch (MS), considering the studied concentrations. However, xanthan (XG) presented a strong relative influence on viscosity and a more significant contribution to the pseudoplasticity and elasticity of the formulations, even at lower concentrations than FG and MS. The influence of MS was mainly relevant in relation to the synergistic interactions with the other two biopolymers, showing the key role of this biopolymer on rheological properties of mixed systems. Regarding the colour, FG exerted more significant influence on colour ( $L^{*}$ and $C^{*}$ ) parameters, when compared with MS and $\mathrm{XG}$, with a significant impact on $\Delta E^{*}$ at high $\mathrm{FG}$ concentration. In addition, it was observed that the glucose released from the thickened beverages based on high MS concentrations upon digestion was considerable, which can delay the recovery of dysphagia patients with problems of obesity and/or diabetes. Thus, thickened beverages based on FG may have advantages in this regard over those based on MS, improving the quality of dysphagia patient's life and diminishing the 
consequences on the nutritional profile of the diets imposed by the treatments to which they are subjected. It is worth mentioning that the analysis of tribological or other mechanical/rheological properties, such as extensional viscosity to analyse the cohesiveness in more depth, deserves to be highlighted in the evaluation of a future product, to fully understand the behaviour of the thickened fluid during swallowing and prevent aspiration.

\section{CRediT author contribution statement}

J.M. Vieira: Conceptualization, Methodology, Formal analysis, Investigation, Writing - original draft. C.C.P. Andrade: Validation, Investigation, (Protimiza and digestibility part). T.P. Santos: Validation, Investigation. P.K. Okuro: Validation, Investigation. S.T. Garcia: Validation. M.I. Rodrigues: Validation. A.A. Vicente: Supervision, Writing- Reviewing and Editing. R.L. Cunha: Conceptualization, Writing- Reviewing and Editing, Project administration, Supervision.

\section{Acknowledgements}

This study was financed by the Coordenação de Aperfeiçoamento de Pessoal de Nível Superior - Brasil (CAPES) (Finance code 001); São Paulo Research Foundation - FAPESP (Process numbers 2016/05448-8; 2011/ 51707-1; EMU 2009/54137-1; 2007/58017-5; 2006/03263-9; 2004/ 08517-3) and by the Conselho Nacional de Desenvolvimento Científico e Tecnológico (CNPq - Process 307168/2016-6). Okuro and Santos thanks São Paulo Research Foundation (FAPESP) (Grant numbers 2018/ 20308-3 and 2017/18109-0).

\section{References}

Abdulmola, N. A., Hember, M. W. N., Richardson, R. K., \& Morris, E. R. (1996). Effect of xanthan on the small-deformation rheology of crosslinked and uncrosslinked waxy maize starch. Carhohydrate Polymers, 31, 65-78.

Achayuthakan, P., \& Suphantharika, M. (2008). Pasting and rheological properties of waxy corn starch as affected by guar gum and xanthan gum. Carbohydrate Polymers, 71(1), 9-17.

Anastasiades, A., Thanou, S., Loulis, D., Stapatoris, A., \& Karapantsios, T. D. (2002). Rheological and physical characterization of pregelatinized maize starches. Journal of Food Engineering, 52, 57-66.

Capitani, M. I., Corzo-Rios, L. J., Chel-Guerrero, L. A., Betancur-Ancona, D. A., Nolasco, S. M., \& Tomás, M. C. (2015). Rheological properties of aqueous dispersions of chia (Salvia hispanica L.) mucilage. Journal of Food Engineering, 149, 70-77.

Chaisawang, M., \& Suphantharika, M. (2006). Pasting and rheological properties of native and anionic tapioca starches as modified by guar gum and xanthan gum. Food Hydrocolloids, 20(5), 641-649.

Choi, H., Mitchell, J. R., Gaddipatia, S. R., Hill, S. E., \& Wolf, B. (2014). Shear rheology and filament stretching behaviour of xanthan gum and carboxymethyl cellulose solution in presence of saliva. Food Hydrocolloids, 40, 71-75.

Choi, H. M., \& Yoo, B. (2009). Steady and dynamic shear rheology of sweet potato starch-xanthan gum mixtures. Food Chemistry, 116(3), 638-643.

Choppe, E., Puaud, F., Nicolai, T., \& Benyahia, L. (2010). Rheology of xanthan solutions as a function of temperature, concentration and ionic strength. Carbohydrate Polymers, 82(4), 1228-1235.

Clavé, P., \& Shaker, R. (2015). Dysphagia: Current reality and scope of the problem. Nature Reviews Gastroenterology \& Hepatology, 12, 259-270.

Cui, W., \& Mazza, G. (1996). Phvsicochemical characteristics of flaxseed gum. Food Research International, 29, 397-402.

Cui, W., Mazza, G., \& Biliaderis, C. G.( (1994). Chemical structure, molecular size distributions, and rheological properties of flaxseed gum. Journal of Agricultural and Food Chemistry, 42(9), 1891-1895.

Cutler, A. N., Morris, E. R., \& Taylor, L. J. (1983). Oral Perception of Viscosity in fluid foods and model systems. 14 pp. 377-395). Food and Nutrition Press.

Dewar, R. J., \& Joyce, M. J. (2006a). The thixotropic and rheopectic behaviour of maize starch and maltodextrin thickeners used in dysphagia therapy. Carbohydrate Polymers, 65, 296-305.

Dewar, R. J., \& Joyce, M. J. (2006b). Time-dependent rheology of starch thickeners and the clinical implications for dysphagia therapy. Dysphagia, 21(4), 264-269.

Ding, H. H., Cui, S. W., Goff, H. D., Wang, Q., Chen, J., \& Han, N. F. (2014). Soluble polysaccharides from flaxseed kernel as a new source of dietary fibres: Extraction and physicochemical characterization. Food Research International, 56, 166-173.

Elboutachfaiti, R., Delattre, C., Anthony Quérro, A., Roulard, R., Julie Duchêne, J., Mesnard, F., et al. (2017). Fractionation and structural characterization of six purified rhamnogalacturonans type I from flaxseed mucilage. Food Hydrocolloids, 62, 273-279.
Englyst, K. N., Englyst, H. N., Hudson, G. J., Cole, T. J., \& Cummings, J. H. (1999). Rapidly available glucose in foods: An in vitro measurement that reflects the glycemic response. American Journal of Clinical Nutrition, 69(3), 448-454.

Farahmandfar, R., Asnaashari, M., Salahi, M. R., \& Rad, T. K. (2017). Effects of basil seed gum, Cress seed gum and Quince seed gum on the physical, textural and rheological properties of whipped cream. International Journal of Biological Macromolecules, 98, $820-828$.

Foster-Powell, K., Holt, S. H., \& Brand-Miller, J. C. (2002). International table of glycemic index and glycemic load values: 2002. American Journal of Clinical Nutrition, 76(1), 5-56.

Garin, N., De Pourcq, J. T., Martín-Venegas, R., Cardona, D., Gich, I., \& Mangues, M. A. (2014). Viscosity differences between thickened beverages suitable for elderly patients with dysphagia. Dysphagia, 29, 483-488.

Germain, I., Dufresne, T., \& Ramaswamy, H. S. (2006). Rheological characterization of thickened beverages used in the treatment of dysphagia. Journal of Food Engineering, 73, 64-74.

Hadde, E. K., \& Chen, J. (2019). Shear and extensional rheological characterization of thickened fluid for dysphagia management. Journal of Food Engineering, 245, 18-23.

Hasanvand, E., \& Rafe, A. (2018). Rheological and structural properties of rice bran protein-flaxseed (Linum usitatissimum L.) gum complex coacervates. Food Hydrocolloids, 83, 296-307.

He, Q., Hort, J., \& Wolf, B. (2016). Predicting sensory perceptions of thickened solutions based on rheological analysis. Food Hydrocolloids, 61, 221-232.

Heyman, B., De Vos, W. H., Depypere, F., Van der Meeren, P., \& Dewettinck, K. (2014). Guar and xanthan gum differentially affect shear induced breakdown of native waxy maize starch. Food Hydrocolloids, 35, 546-556.

Hori, K., Hayashi, H., Yokoyama, S., Ono, T., Ishihara, S., Magara, J., et al. (2015). Comparison of mechanical analyses and tongue pressure analyses during squeezing and swallowing of gels. Food Hydrocolloids, 44, 145-155.

Jo, W., Bak, J. H., \& Yoo, B. (2018). Rheological characterizations of concentrated binary gum mixtures with xanthan gum and galactomannans. International Journal of Biological Macromolecules, 114, 263-269.

Kanmani, N., Romano, N., Ebrahimi, M., Amin, S. M. N., Kamarudin, M. S., Karami, A., et al. (2018). Improvement of feed pellet characteristics by dietary pre-gelatinized starch and their subsequent effects on growth and physiology in tilapia. Food Chemistry, 239, 1037-1046.

Kim, C., \& Yoo, B. (2006). Rheological properties of rice starch-xanthan gum mixtures. Journal of Food Engineering, 75(1), 120-128.

Koocheki, A., Reza-Taherian, A., \& Bostan, A. (2013). Studies on the steady shear flow behavior and functional properties of Lepidium perfoliatum seed gum. Food Research International, 50, 446-456.

Leonard, R. J., White, C., McKenzie, S., \& Belafsky, P. C. (2013). Effects of bolus rheology on aspiration in patients with dysphagia. Journal of the Academy of Nutrition and Dietetics, 2212-2672.

Li, X. Y., Li, D., Wang, L. J., Wu, M., \& Adhikari, B. (2012). The effect of addition of flaxseed gum on the rheological behavior of mixed flaxseed gum-casein gels. Carbohydrate Polymers, 88(4), 1214-1220.

Liu, J., Shim, Y. Y., Poth, A. G., \& Reaney, M. J. T. (2016). Conlinin inflaxseed (Linum usitatissimumL.) gum and its contribution to emulsification properties. Food Hydrocolloids, 52, 963-971.

Mackley, M. R., Tock, C., Anthony, R., Butler, S. A., Chapman, G., \& Vadillo, D. C. (2013). The rheology and processing behavior of starch and gum-based dysphagia thickeners. Journal of Rheology, 57(6), 1533-1553.

Mandala, I., \& Palogou, E. (2003). Effect of preparation conditions and starch/xanthan concentration on gelation process of potato starch systems. International Journal of Food Properties, 6, 311-328.

Mandala, I. G., Palogou, E. D., \& Kostaropoulus, A. E. (2002). Influence of preparation and storage conditions on texture of xanthan-starch mixtures. Journal of Food Engineering, 53, 27-38.

Mandala, I. G., Savvas, T. P., \& Kostaropoulos, A. E. (2004). Xanthan and locust bean gum influence on the rheology and structure of a white model-sauce. Journal of Food Engineering, 64(3), 335-342.

Meng, Y., Rao, M. A., \& Datta, K. (2005). Computer simulation of the pharyngeal bolus transport of Newtonian and Non-Newtonian fluids Food and Bioproducts Processing, 83 (4), 297-305.

Minekus, M., Alminger, M., Alvito, P., Bohn, T., Ballance, S., Bourlieu, C., et al. (2014). A standardised static in vitro digestion method suitable for food - an international consensus. Food \& Function, 5, 1113-1124.

Moczkowska, M., Karpa, S., Niu, Y., \& Kureka, M. A. (2019). Enzymatic, enzymaticultrasonic and alkaline extraction of soluble dietary fibre from flaxseed - a physicochemical approach. Food Hydrocolloids, 90, 105-112.

Moret-Tatay, A., Rodríguez-García, J., Martí-Bonmat, E., Hernando, I., \& Hernández, M. J. (2015). Commercial thickeners used by patients with dysphagia: Rheological and structural behaviour in different food matrices. Food Hydrocolloids, $51,318-326$.

Morris, D. H., \& Vaisey-Genser, M. (2003). FLAXSEED. Encyclopedia of food sciences and nutrition (2nd ed.).

Nishinari, K., Turcanu, M., Nakauma, M., \& Fang, Y. (2019). Role of fluid cohesiveness in safe swallowing. Science of Food, 3, 5.

Olivas, G. I., \& Barbosa-Cánovas, G. V. (2005). Edible coatings for fresh-cut fruits. Critical Reviews in Food Science and Nutrition, (45), 657-670.

Ong, J. J.-X., Steele, C. M., \& Duizer, L. M. (2018). Sensory characteristics of liquids thickened with commercial thickeners to levels specified in the International Dysphagia Diet Standardization Initiative (IDDSI) framework. Food Hydrocolloids, $79,208-217$. 
O'Leary, M., Hanson, B., \& Smith, C. (2010). Viscosity and non-Newtonian features of thickened fluids used for dysphagia therap. Journal of Food Science, 75(6), 330-338.

Qian, K. Y., Cui, S. W., Wu, Y., \& Goff, H. D. (2012). Flaxseed gum from flaxseed hulls: Extraction, fractionation, and characterization. Food Hydrocolloids, 28(2), 275-283.

Richardson, R. K., Morris, E. R., Ross-Murphy, S. B., Taylor, L. J., \& Dea, I. C. M. (1989) Characterization of the perceived texture of thickened systems by dynamic viscosity measurements. Food Hidrocolloids, 3, 175-191.

Russ, N., Zielbauer, B. I., Ghebremedhin, M., \& Vilgis, T. A. (2016). Pre-gelatinized tapioca starch and its mixtures with xanthan gum and 1-carrageenan. Food Hydrocolloids, 56, 180-188.

September, C., Nicholson, T. M., \& Cichero, J. A. Y. (2014). Implications of changing the amount of thickener in thickened infant formula for infants with dysphagia. Dysphagia, 29, 432-437.

Shama, F., \& Sherman, P. (1973). Identification of stimuli controlling the sensory evaluation of viscosity II. Oral methods. Journal of Texture Studies, 4(1), 111-118.

Song, K., Kim, Y., \& Chang, G. (2006). Rheology of concentrated xanthan gum solutions: Steady shear flow behaviour. Fibers and Polymers, 7(2), 129-138.

Steffe, J. F. (1996). Rheological methods in food process engineering (2nd ed.). East Lansing: Freeman Press.

Szczesniak, A. S., \& Farkas, E. (1963). Objective characterization of the mouth feel of gum solutions. Journal of Food Science, 27, 381-385.

Tako, M., Tamaki, Y., Teruya, T., \& Takeda, Y. (2014). The principles of starch gelatinization and retrogradation. Food and Nutrition Sciences, 5, 280-291.
Tester, R. F., Karkalas, J., \& Qi, X. (2004). Starch-composition, fine structure and architecture. Journal of Cereal Science, 39(2), 151-165.

Torres, O., Yamada, A., Rigby, N. M., Hanawa, T., Kawano, Y., \& Sarkar, A. (2019). Gellan gum: A new member in the dysphagia thickener family. Biotribology, 17, 8-18.

Vallons, K. J. R., Helmens, H. J., \& Oudhuis, A. A. C. M. (2015). Effect of human saliva on the consistency of thickened drinks for individuals with dysphagia. International Journal of Language \& Communication Disorders, 50(2), 165-175.

Veiga, P. G., Cunha, R. L., Viotto, W. H., \& Penetate, A. J. (2000). Cacracterização química, reológica e aceitação sensorial do queijo petit suisse brasileiro. Ciência e Tecnologia de Alimentos, 20(3), 349-357.

Vieira, J. M., Mantovani, R. A., Raposo, M. F. J., Coimbra, M. A., Vicente, A. A., \& Cunha, R. L. (2019). Effect of extraction temperature on rheological behavior and antioxidant capacity of flaxseed gum. Carbohydrate Polymers, 213, 217-227.

Vieira, J. M., Oliveira, D. B., Jr., Maffezzolli, G. P., de Mello, J. D. B., Vicente, A. A., \& Cunha, R. L. (2020). Rheology and soft tribology of thickened dispersions aiming the development of oropharyngeal dysphagia-oriented products. Current Research in Food Science, 3, 19-29.

Wood, G. N. (1968). Centric occlusion, centric relation, and the mandibular posture. The Journal of Prosthetic Dentistry, 20(4), 292-306.

Zargaraan, A., Rastmanesh, R., Fadavi, G., Zayeri, F., \& Mohammadifar, M. A. (2013) Rheological aspects of dysphagia-oriented food products: A mini review. Food Science and Human Wellness, 2, 173-178. 